\title{
How Placebos Change the Patient's Brain
}

\author{
Fabrizio Benedetti ${ }^{\star,}$, Elisa Carlino ${ }^{1}$ and Antonella Pollo ${ }^{1}$ \\ ${ }^{1}$ Department of Neuroscience, University of Turin Medical School, and National Institute of Neuroscience, Turin, Italy
}

\begin{abstract}
Although placebos have long been considered a nuisance in clinical research, today they represent an active and productive field of research and, because of the involvement of many mechanisms, the study of the placebo effect can actually be viewed as a melting pot of concepts and ideas for neuroscience. Indeed, there exists not a single but many placebo effects, with different mechanisms and in different systems, medical conditions, and therapeutic interventions. For example, brain mechanisms of expectation, anxiety, and reward are all involved, as well as a variety of learning phenomena, such as Pavlovian conditioning, cognitive, and social learning. There is also some experimental evidence of different genetic variants in placebo responsiveness. The most productive models to better understand the neurobiology of the placebo effect are pain and Parkinson's disease. In these medical conditions, the neural networks that are involved have been identified: that is, the opioidergic-cholecystokinergic-dopaminergic modulatory network in pain and part of the basal ganglia circuitry in Parkinson's disease. Important clinical implications emerge from these recent advances in placebo research. First, as the placebo effect is basically a psychosocial context effect, these data indicate that different social stimuli, such as words and rituals of the therapeutic act, may change the chemistry and circuitry of the patient's brain. Second, the mechanisms that are activated by placebos are the same as those activated by drugs, which suggests a cognitive/affective interference with drug action. Third, if prefrontal functioning is impaired, placebo responses are reduced or totally lacking, as occurs in dementia of the Alzheimer's type.

Neuropsychopharmacology Reviews (2011) 36, 339-354; doi: 10. 1038/npp.20 10.81; published online 30 June 2010
\end{abstract}

Keywords: placebo; nocebo; anxiety; reward; learning; genetics

\section{INTRODUCTION}

Placebos are not inert substances, as thus far believed. They are made of words and rituals, symbols, and meanings, and all these elements are active in shaping the patient's brain. Inert substances, such as saline solution, have long been used in clinical trials and double-blind randomized protocols to assess the efficacy of new therapies, for example, new pharmacological agents. Although inert substances are of great validity in the clinical trial setting, the clinical trialists have always drawn their attention on the inert substance itself, thus diverting it from the real meaning of placebo (Moerman, 2002). The placebo is not the inert substance alone, but rather its administration within a set of sensory and social stimuli that tell the patient that a beneficial treatment is being given. If drawing attention to the inert substance is correct in pragmatic clinical trials, in which the only purpose is to see whether drugs are better than

${ }^{*}$ Correspondence: Professor F Benedetti, Department of Neuroscience, University of Turin Medical School, and National Institute of Neuroscience, Corso Raffaello 30, 10125 Turin, Italy, Tel: +39011670 8492, Fax: + 39011670 8174, E-mail: fabrizio.benedetti@unito.it Received 28 February 2010; revised 25 April 2010; accepted 9 May 2010 placebos, this surely does not help understand what a placebo is (Benedetti, 2008a).

A real placebo effect is a psychobiological phenomenon occurring in the patient's brain after the administration of an inert substance, or of a sham physical treatment such as sham surgery, along with verbal suggestions (or any other cue) of clinical benefit (Price et al, 2008). Therefore, the effect that follows the administration of a placebo cannot be attributable to the inert substance alone, for saline solutions or sugar pills will never acquire therapeutic properties. Instead, the effect is because of the psychosocial context that surrounds the inert substance and the patient. In this sense, to the clinical trialist and to the neurobiologist, the term 'placebo effect' has different meanings. Whereas the former is interested in any improvement that may occur in the group of patients who take the inert substance, regardless of its origin, the latter is only interested in the improvement that derives from active processes occurring in the patient's brain. In fact, the improvement in patients who are given a placebo can be ascribed to a vast array of factors, such as spontaneous remission of the disease (the so-called natural history), regression to the mean (a statistical phenomenon due to selection biases), patient's and doctor's biases, and unidentified effects of co-interventions 
(Figure 1). In pragmatic clinical trials, the trialists are interested in the improvement irrespective of its cause, because they only need to establish whether the patients who take the true treatment, be it pharmacological or not, are better off than those who take the placebo. This pragmatic approach yields fruitful results in clinical trials. However, if we are interested in understanding what a real placebo effect is and how it works, we need to separate it from spontaneous remissions, regression to the mean, biases, and so on (Benedetti, 2008a).

Taking all these considerations into account, this review deals only with a portion of the improvement that may take place in the placebo group of a clinical trial, that is, the improvement because of active processes in the patient's brain (the real placebo effect; Figure 1). It is possible to rule out other phenomena using the appropriate methodological approach. For example, to rule out spontaneous remission, the placebo group must be compared with a no-treatment group, which gives us information on the natural history of the disease. Similarly, to rule out biases, such as those that may occur in subjective symptoms such as pain, objective outcome measures must be assessed. From this methodological perspective, placebo research is not easy to perform, for it requires rigorous experimental protocols and plenty of control groups.

The real placebo response, that is, the real psychobiological phenomenon, is not irrelevant. Its contribution to the clinical improvement is substantial. For example, in antidepressant clinical trials, it has been shown that the natural history of the disease (ie, spontaneous remission) accounts for $23.87 \%$ of the overall effect, the real placebo effect (ie, expectations of benefit) for $50.97 \%$, and the drug effect for $25.16 \%$ only (Kirsch and Sapirstein, 1998). Therefore, in clinical trials for major depression, one-quarter of the benefit is due to the specific action of the active medication, one-quarter is due to other factors such as spontaneous remission, and one-half is the real placebo effect, that is, the real psychobiological phenomenon.

Today, this experimental approach to the placebo effect is paying dividends and bodes well for the future (Finniss et al, 2010). As emphasized in this review, we now know that there is not a single but many placebo effects, with different mechanisms and in different diseases, systems, and therapeutic interventions (Benedetti, 2008b; Enck et al, 2008). In other words, different processes may be at work in the patient's brain in different conditions. Sometimes it is anxiety that is modulated, at some other times reward mechanisms are involved, and in some other circumstances different types of learning, or even genetic variants, may take place in placebo responsiveness. In this sense, the placebo effect is a melting pot of neuroscientific concepts and ideas, ranging from anxiety and reward mechanisms to Pavlovian conditioning and social learning, and from neurogenetics and neurophysiology to clinical practice and neuroethics.

\section{EXPECTATIONS OF THERAPEUTIC BENEFIT}

The terms placebo effect and placebo response are often used as synonymous, and thus both terms will be used in this study. Most of the research on placebos has focused on expectations as the main factor involved in placebo responsiveness. In many studies in the literature in which expectations are analyzed, the terms 'effects of placebos' and 'effects of expectations' are frequently used interchangeably. In general, expectation is aimed at preparing the body to anticipate an event to better cope with it, and as

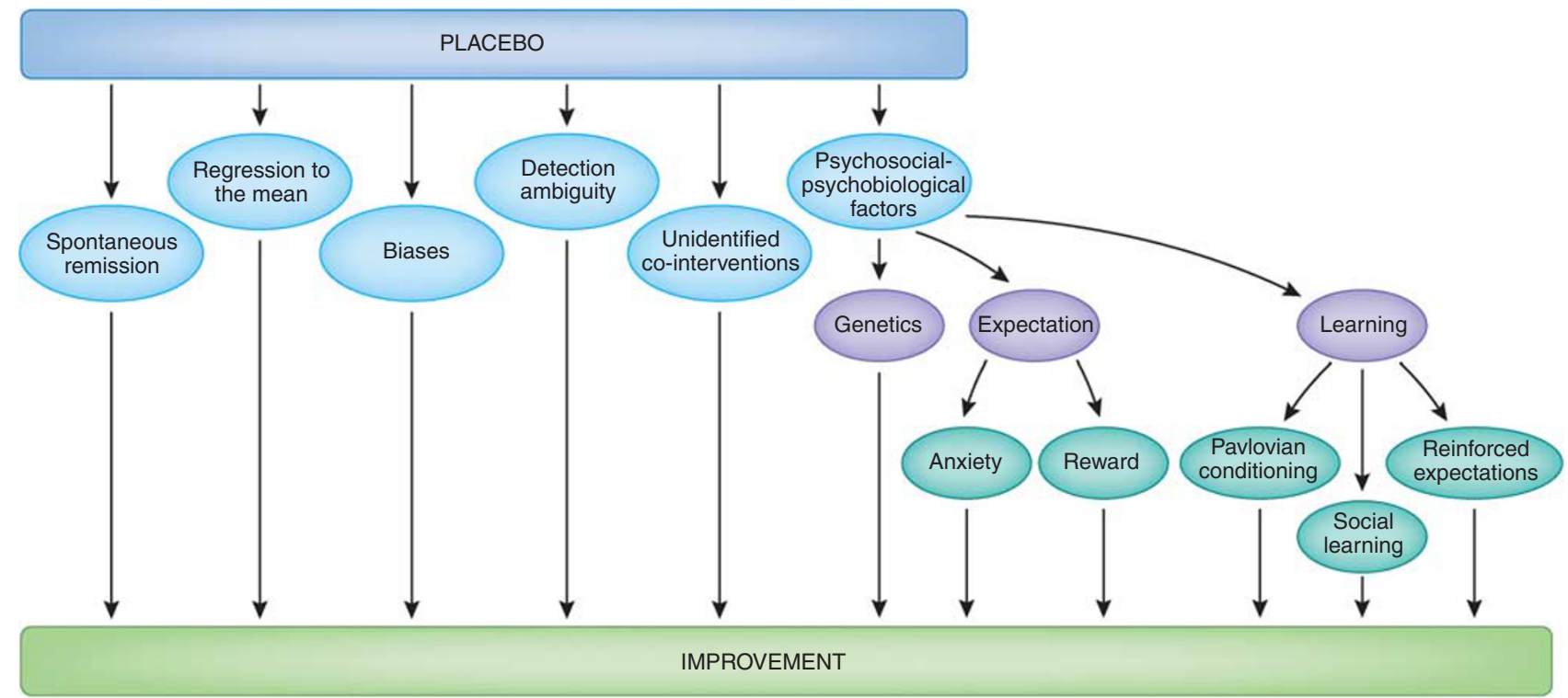

Figure 1. After the administration of a placebo, a clinical improvement may occur for a variety of reasons. Whereas the clinical trialist is interested in any improvement that may take place in a clinical trial, the neurobiologist is only interested in the psychosocial-psychobiological effects after the administration of a placebo. These include a number of mechanisms, such as anxiety, reward, learning, and genetics. 
such offers a clear evolutionary advantage. For example, the expectation of a future outcome and of a future response can be held by an individual about one's own emotional and physiological responses such as pain, anxiety, and sexual arousal (Kirsch, 1999). It can then lead to a cognitive reassessment of the appropriate conduct, with positive expectations leading to adopt a particular behavior, for example, resuming a normal daily schedule, and negative expectations leading to its inhibition (Bootzin, 1985; Bandura, 1997).

Expectations are unlikely to operate alone, and several other factors and mechanisms have been identified, such as memory and motivation (Price et al, 2008). The effects of expectations may also be modulated by changes in other cognitive processes, such as a decrease in self-defeating thoughts (Stewart-Williams and Podd, 2004). In addition, Frank (1971) analyzed the healing process within the context of patient's expectations, and proposed that hope is the primary mechanism of change in psychotherapy. Indeed, hope can be defined as the desire and expectation that the future will be better than the present. Expectations may also have a role in the Hawthorne effect, that is, the clinical improvement in a group of patients in a clinical trial that is attributable to the fact of being under study (Last, 1983). In other words, a patient who knows to be under scrutiny may expect a better therapeutic benefit because of the many exams that he or she undergoes, the special attention by the medical personnel, and the trust in the new therapy under investigation. Therefore, expectation is a general term that can be described from many different perspectives.

There are several mechanisms through which expectation of a future event may affect different physiological functions. For example, the expectation of a negative outcome is aimed at anticipating a possible threat, thus increasing anxiety, whereas the expectation of a forthcoming positive outcome may reduce anxiety and/or activate the neuronal networks of reward mechanisms. Indeed, there is ample support for a role of both anxiety and reward mechanisms in placebo responsiveness, some of which is outlined below.

\section{Modulation of Anxiety by Expectations}

Anxiety has been found to be reduced after placebo administration in some studies. If one expects a distressing symptom to subside shortly, anxiety tends to decrease. For example, early studies by McGlashan et al (1969) and Evans (1977) investigated experimental pain in both trait and state anxiety subjects. Trait anxiety represents a personality trait and thus can be found throughout life, whereas state anxiety may be present in specific stressful situations and represents an adaptive and transitory response to stress. These researchers gave the subjects a placebo that they believed to be a painkiller. Whereas no correlation was found between trait anxiety and pain tolerance after placebo administration, a correlation occurred between situational anxiety and pain tolerance during the placebo session. Similar results were obtained more recently by Vase et al (2005), who found decreased anxiety levels in patients with irritable bowel syndrome who received a placebo treatment.

In brain imaging studies, reduced activation of anxietyrelated areas during a placebo response could be observed. In one functional magnetic resonance imaging (fMRI) study, it was found that placebo treatments can modulate emotions (Petrovic et al, 2005). On the first day of the experiment, subjects were treated with either the benzodiazepine, midazolam, or the benzodiazepine receptor antagonist, flumazenil, before the presentation of pictures that induced unpleasantness. As expected, whereas midazolam reduced the unpleasantness, flumazenil reversed this effect. Therefore, on the first day strong expectations of the treatment effect were induced. On the second day, the subjects were told that they would be treated either with the same antianxiety drug or the anxiolytic blocker as the previous day. However, instead of receiving the real medication, they received a placebo. A significant and robust placebo response (reduced unpleasantness) was found when the subjects thought that they had been treated with the anxiolytic drug, whereas no response occurred if they thought they had received the anxiolytic blocker. fMRI showed that regional blood flow changed in both the anterior cingulate cortex and lateral orbitofrontal cortex, which are the very same areas also involved in placebo analgesia (Petrovic et al, 2002; Wager et al, 2004). This suggests that similar mechanisms might be at work in the placebo response of emotional stimuli and in placebo analgesia.

The best evidence that anxiety takes part in placebo responses is shown by the nocebo effect, which is opposite to the placebo effect. To induce a nocebo effect, an inert substance is administered along with negative verbal suggestions of clinical worsening, for example, pain increase. A study by Colloca et al (2008) used a nocebo procedure, in which verbal suggestions of painful stimulation were given to healthy volunteers before administration of either tactile or low-intensity painful electrical stimuli. This study showed that these anxiogenic verbal suggestions were capable of turning tactile stimuli into pain, as well as low-intensity painful stimuli into high-intensity pain. Therefore, by defining hyperalgesia as an increase in pain sensitivity and allodynia as the perception of pain in response to innocuous stimulation, nocebo suggestions of a negative outcome can produce both hyperalgesic and allodynic effects.

Overall, expectations of a negative outcome, such as pain increase, may result in the amplification of pain, and several brain regions, such as the anterior cingulate cortex, the prefrontal cortex, the insula, and the hippocampus, have been found to be activated during the anticipation of pain in a variety of studies (Koyama et al, 1998, 2005; Chua et al, 1999; Hsieh et al, 1999; Ploghaus et al, 1999, 2001; Sawamoto et al, 2000; Porro et al, 2002, 2003; Lorenz et al, 2005; Keltner et al, 2006). These effects are opposite to 
those elicited by positive expectations, in which subjects expect pain reduction. In some studies, in which both positive and negative outcomes have been investigated with the same experimental approach, the modulation of both subjective experience and brain activation has been found. For example, in the study by Koyama et al (2005), as the magnitude of expected pain increased, activation increased in the thalamus, insula, prefrontal cortex, and anterior cingulate cortex. In contrast, expectations of decreased pain reduced activation of pain-related brain regions, such as the primary somatosensory cortex, the insular cortex, and anterior cingulate cortex. In a different study by Keltner et al (2006), it was found that the level of expected pain intensity alters perceived pain intensity along with the activation of different brain regions. Using two visual cues, each conditioned to one of two noxious thermal stimuli (high and low), the researchers showed that subjects reported higher pain when the noxious stimulus was preceded by the high-intensity visual cue. By comparing the brain activations produced by the two visual cues, these researchers found significant differences in the ipsilateral caudal anterior cingulate cortex, the head of the caudate, the cerebellum, and the contralateral nucleus cuneiformis.

Kong et al (2008) also boosted negative expectations about pain perception after sham acupuncture, in a protocol involving objective fMRI, and subjective pain, and expectation measurements. When comparing responses to thermal painful stimuli of equal intensity delivered at control sites or at sites along the suggested course of an acupuncture meridian (nocebo), they obtained increased pain reports for the nocebo sites, together with increased activity in several areas of the medial pain matrix (among which bilateral dorsal anterior cingulate cortex, insula, left frontal and parietal operculum, orbital prefrontal cortex, and hippocampus). They advocated for the left hippocampus (never shown so far to be involved in placebo analgesia) a specific role in nocebo hyperalgesia, supported by the correlation of its activity with that of left orbital prefrontal gyrus and anterior cingulate cortex, known to have a key role in the cognitive modulation of the emotional component of pain. Interestingly, the hippocampus has also been directly linked to anxiety, as its activity increases when inducing anxiety about impending stimuli (Ploghaus et al, 2001).

Nocebo hyperalgesia has also been studied in some detail from a pharmacological perspective to identify possible neurotransmitters that are involved in anxiety-induced pain increase. Using an anxiogenic nocebo procedure, in which an inert treatment is given along with verbal suggestions of pain worsening, Benedetti et al (1997) gave proglumide, a nonspecific cholecystokinin (CCK) antagonist for both CCK-A and CCK-B receptors, or CCK-1 and CCK-2 according to the new classification (Noble et al, 1999), to postoperative patients during a postsurgical manipulation. Anxiety (nocebo)-induced hyperalgesia was found to be prevented by proglumide in a dose-dependent manner, thus suggesting CCK mediation. This effect was not antagonized by naloxone, thus indicating that it is not mediated by opioids. To overcome some ethical limitations that were present in this clinical study, a similar experimental approach was used in healthy subjects. By investigating experimental ischemic arm pain, Benedetti et al (2006a) performed a detailed neuropharmacological study of anxiety (nocebo)-induced hyperalgesia. It was found that the oral administration of an inert substance, along with verbal suggestions of hyperalgesia, induced hyperalgesia and hyperactivity of the hypothalamic-pituitary-adrenal axis, as assessed using adrenocorticotropic hormone (ACTH) and cortisol plasma concentrations. Both noceboinduced hyperalgesia and hypothalamus-pituitary-adrenal hyperactivity were blocked by the benzodiazepine, diazepam, thereby suggesting an involvement of anxiety. In contrast, the administration of the mixed CCK type-A/B receptor antagonist, proglumide, blocked nocebo hyperalgesia completely, but had no effect on hypothalamuspituitary-adrenal hyperactivity. This suggests a specific involvement of CCK in the hyperalgesic but not in the anxiety component of the nocebo effect. Neither diazepam nor proglumide showed analgesic properties on baseline pain, as they acted on the anxiety-induced pain increase only.

Similar mechanisms are present in animals, thus raising important questions about the possible use of animal models to study placebo and nocebo effects. For example, in a social-defeat model of anxiety in rats, it was shown that CI-988, a selective CCK-B receptor antagonist, prevents anxiety-induced hyperalgesia, with an effect that is similar to that produced by the anxiolytic drug, chlordiazepoxide (Andre et al, 2005). Similarly, other studies that used selective CCK-A and CCK-B receptor antagonists in animals and humans have shown the important role of CCKergic systems in the modulation of anxiety and in the link between anxiety and hyperalgesia (Benedetti and Amanzio, 1997; Hebb et al, 2005). The pro-nociceptive and antiopioid action of CCK has been documented in the brainstem in animals (Mitchell et al, 1998; Heinricher et al, 2001; Heinricher and Neubert, 2004), and in the rostroventromedial medulla of the rat, there are neurons expressing both $\mu$-opioid receptors and CCK-2 (or CCK-B) receptors. Over $80 \%$ of these cells coexpress both receptors, whereas approximately $15 \%$ express only CCK-2, and very few cells express $\mu$-opioid receptors only. Selective lesions of CCK-2 and $\mu$-opioid-expressing cells do not alter the basal sensory thresholds but abolish the hyperalgesia induced by microinjection of CCK into the rostroventromedial medulla, which suggests that these CCK- $2 / \mu$-opioid coexpressing rostroventromedial neurons facilitate pain and can be directly activated by CCK input to the rostroventromedial medulla (Zhang et al, 2009).

It is worth noting that although in anxiety-induced hyperalgesia the anxiety is about the pain itself, in stressinduced analgesia the anxiety is about a stressor that shifts the attention from the pain itself, for example, toward a threatening stimulus in the environment. Therefore, directed attention has a key role (Colloca and Benedetti, 2007). In 
the case of anxiety-induced hyperalgesia, in which attention is focused on the impending pain, the biochemical link between this anticipatory anxiety and the pain increase is represented by the CCKergic systems. Conversely, in stressinduced analgesia a general state of arousal stems from a stressful situation in the environment, so that attention is now focused on the environmental stressor. In this case, there is experimental evidence that analgesia results from the activation of the endogenous opioid systems (Willer and Albe-Fessard, 1980; Terman et al, 1986; Flor and Grüsser, 1999).

\section{Expectation of Reward}

Not only can expectations of future events modulate anxiety, but they may also induce physiological changes through reward mechanisms. These mechanisms are mediated by specific neuronal circuits linking cognitive, emotional, and motor responses, and are traditionally studied in the context of the pursuit of natural (eg, food), monetary, and drug rewards (Mogenson and Yang, 1991; Kalivas et al, 1999). In animals, dopaminergic cells in the brainstem ventral tegmental area projecting to the nucleus accumbens of the ventral basal ganglia respond to both the magnitude of anticipated rewards and deviations from the predicted outcomes, thus representing an adaptive system modulating behavioral responses (Setlow et al, 2003; Tobler et al, 2005; Schultz, 2006). The nucleus accumbens has a central role in the dopamine-mediated reward mechanisms together with the ventral tegmental area. However, it should be noted that other regions are also involved, such as the amygdala, the periacqueductal gray, and other areas in the thalamic, hypothalamic, and subthalamic (pallidum) regions.

There is compelling experimental evidence that the mesolimbic dopaminergic system may be activated in some circumstances when a subject expects clinical improvement after placebo administration. In 2001, de la FuenteFernandez et al (2001) assessed the release of endogenous dopamine using positron emission tomography (PET) with raclopride, a radiotracer that binds to dopamine D2 and D3 receptors, competing with endogenous dopamine. In this study, Parkinsonian patients were aware that they would be receiving an injection of either active drug (apomorphine, a dopamine receptor agonist) or placebo, according to classical clinical trial methodology. After placebo administration, it was found that dopamine was released in the striatum, corresponding to a change of $\geqslant 200 \%$ in extracellular dopamine concentration and comparable to the response to amphetamine in subjects with an intact dopamine system. The release of dopamine in the motor striatum (putamen and dorsal caudate) was greater in those patients who reported clinical improvement. Although in the studies by de la Fuente-Fernandez et al $(2001,2002)$ all patients showed dopamine placebo responses, only half of the patients reported concomitant motor improvement. These patients also released larger amounts of dopamine in the dorsal motor striatum, suggesting a relationship between the amount of dorsal striatal dopamine release and clinical benefit. This relationship was not present in the ventral striatum, that is, in the nucleus accumbens, in which all patients showed increased dopamine release, irrespective of whether they perceived any improvement. Accordingly, the investigators proposed that the dopamine released in the nucleus accumbens was associated with the patients' expectation of improvement in their symptoms, which could in turn be considered a form of reward.

In 2002, another brain imaging study was carried out (Mayberg et al, 2002). Changes in brain glucose metabolism were measured using PET in patients with unipolar depression who were treated with either placebo or fluoxetine for 6 weeks. Common and unique responses were described. In fact, both placebo and fluoxetine treatment induced regional metabolic increases in the prefrontal, anterior cingulate, premotor, parietal, posterior insula, and posterior cingulate, and metabolic decreases in the subgenual, para-hippocampus, and thalamus. The magnitude of regional fluoxetine changes was generally greater than placebo. However, fluoxetine responses were associated with additional subcortical and limbic changes in the brainstem, striatum, anterior insula, and hippocampus. There were no regional changes unique to placebo at 6 weeks. Interestingly, unique ventral striatal (nucleus accumbens) and orbital frontal changes were present in both placebo and drug responders at 1 week of treatment, that is, well before the onset of clinical benefit. Thus, these changes were not associated with the clinical response, but rather with expectation and anticipation of the clinical benefit. Moreover, such changes could not be observed in either the eventual drug nonresponders at 1 week or in drug responders at 6 weeks, when the antidepressant response was well established, consistent with an expectation pattern of response (Mayberg et al, 2002; Benedetti et al, 2005).

In another brain imaging study, in which both PET and fMRI were used, Scott et al (2007) tested the correlation between the responsiveness to placebo and that to monetary reward. Using a model of experimental pain in healthy subjects, they found that placebo responsiveness was related to the activation of dopamine in the nucleus accumbens, as assessed using in vivo receptor binding PET with raclopride. The very same subjects were then tested with fMRI for monetary responses in the nucleus accumbens. A correlation between the placebo responses and the monetary responses was found: the larger the responses of nucleus accumbens to monetary reward, the stronger its responses to placebos. The same group (Scott et al, 2008) studied the endogenous opioid and the dopaminergic systems in different brain regions, including the nucleus accumbens. Subjects underwent a pain challenge twice, in the absence and presence of a placebo with expected analgesic properties. Using PET with ${ }^{11} \mathrm{C}$-labeled raclopride for the analysis of dopamine and ${ }^{11} \mathrm{C}$-carfentanil for the study of opioids, it was found that placebo induced activation of opioid neurotransmission in the anterior cingulate, orbitofrontal 
and insular cortices, nucleus accumbens, amygdala, and periaqueductal gray matter. Dopaminergic activation was observed in the ventral basal ganglia, including the nucleus accumbens. Both dopaminergic and opioid activity were associated with both anticipation and perceived effectiveness of the placebo. Large placebo responses were associated with greater dopamine and opioid activity in the nucleus accumbens. Conversely, pain increase-related nocebo responses were associated with a deactivation of dopamine and opioids. Therefore, placebo and nocebo effects seem to be associated with opposite responses of dopamine and endogenous opioids in a distributed network of regions that form part of the reward and motivation circuit. Similar results have been obtained more recently (Schweinhardt et al, 2009).

\section{The Neural Network of Placebo Analgesia}

Several neuropharmacological and neuroimaging studies investigated neither anxiety nor reward mechanisms, making it impossible to state specifically whether the observed placebo responses were attributable to a reduction in anxiety or to the activation of the reward circuitry. In all probability, here too anxiety and/or reward mechanisms have a role, depending on the experimental condition. In any case, these studies have provided evidence that a complex neural network is involved during the placebo analgesic and the nocebo hyperalgesic responses. The proposed circuitry is depicted in Figure 2. Pain transmission is inhibited by a descending pain modulating system that originates in the cerebral cortex. In fact, several cortical areas have been found to be activated by placebo administration, such as the anterior cingulate cortex and the dorsolateral prefrontal cortex (Petrovic et al, 2002; Wager et al, 2004). This activation then extends into the whole descending pain modulating system, involving the hypothalamus, the periaqueductal gray, and the rostroventromedial medulla (Eippert et al, 2009a), and reaches down to the spinal cord in which inhibition of dorsal horn neurons is likely to occur (Eippert et al, 2009b). Neuropharmacological studies have shown that this system is opioidergic, for opioid antagonists block placebo analgesia (Levine et al, 1978; Benedetti, 1996; Amanzio and Benedetti, 1999; Eippert et al, 2009a), and in vivo receptor binding has shown activation of $\mu$-opioid receptors during placebo analgesia (Zubieta et al, 2005; Wager et al, 2007). The dopaminergic reward system, in which dopaminergic neurons in the ventral tegmental area project to the nucleus accumbens, is also involved (Scott et al, 2007, 2008). These opioidergic and dopaminergic networks are antagonized by at least two mechanisms, which are at the basis of nocebo hyperalgesia. On the one hand, a CCKergic system has been suggested to antagonize the opioidergic circuit at different levels, for example, in the rostroventromedial medulla (Benedetti et al, 1997, 2006a). On the other hand, deactivation of $\mu$-opioids and D2-D3 dopamine receptors

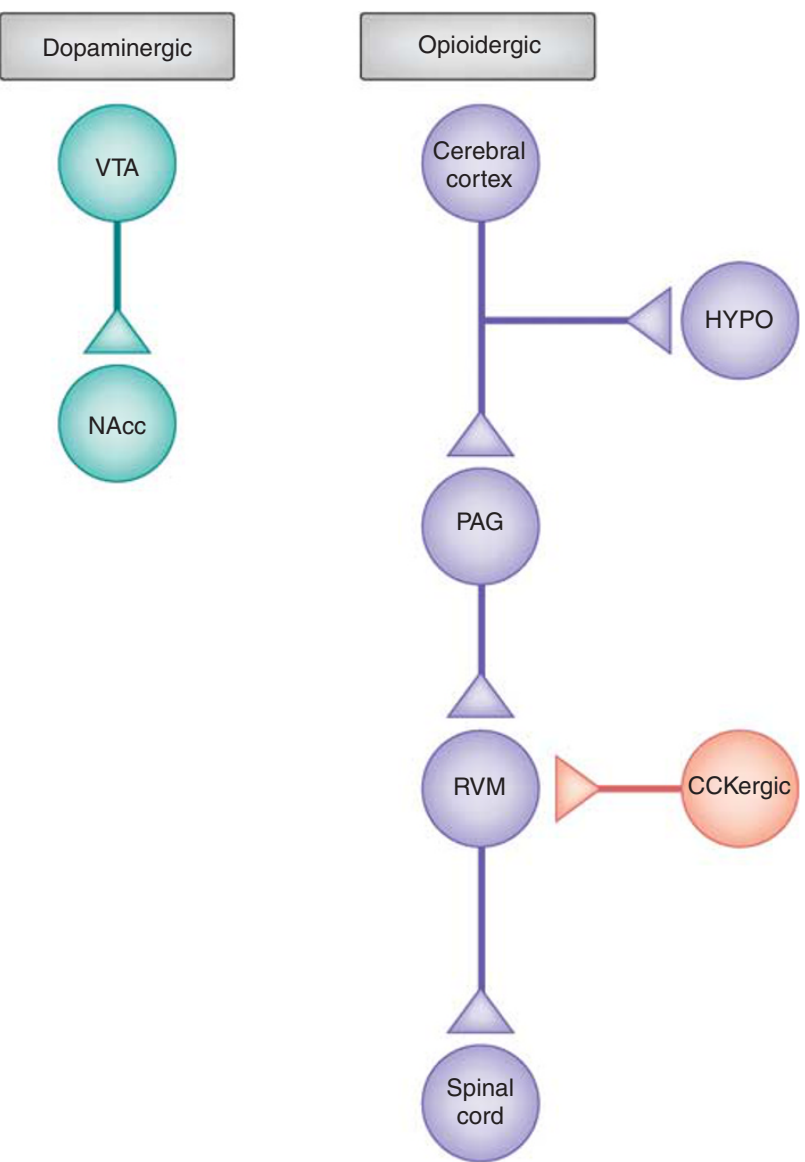

Figure 2. Neural network involved in placebo analgesia and nocebo hyperalgesia. A descending pain inhibitory opioidergic system starts from the cerebral cortex and goes down to the hypothalamus (HYPO), periaqueductal gray (PAG), rostroventromedial medulla (RVM), and spinal cord. The dopaminergic reward system, in which dopaminergic neurons in the ventral tegmental area (VTA) project to the nucleus accumbens (NAcc), is also involved. These opioidergic and dopaminergic networks are antagonized by at least two mechanisms, which are at the basis of nocebo hyperalgesia. On one hand, a cholecystokininergic (CCKergic) system antagonizes the opioidergic circuit at different levels, for example, in the rostroventromedial medulla. On the other hand, deactivations of $\mu$-opioids and D2-D3 dopamine receptors occur in the nucleus accumbens during nocebo hyperalgesia.

occur in the nucleus accumbens during nocebo hyperalgesia (Scott et al, 2008).

\section{LEARNING TO RESPOND TO PLACEBOS}

Learning is another mechanism that is central to placebo responsiveness. Subjects who suffer from a painful condition, such as headache, and who regularly consume aspirin, can associate the shape, color, and taste of the pill with pain decrease. After repeated associations, if they are given a sugar pill resembling aspirin, they will experience pain decrease. Not only can shape, color, and taste of pills be associated with clinical improvement, but also countless other stimuli, such as hospitals, diagnostic, and therapeutic equipments, and medical personnel features. The mechanism 
that underlies this effect is conditioning, in which a conditioned (neutral) stimulus, for example, the color and shape of a pill, can become effective in inducing the reduction of a symptom if repeatedly associated with an unconditioned stimulus, that is, the active principle contained in the pill. This type of associative learning may represent the basis of many placebo effects, in which the placebo is the conditioned (neutral) stimulus itself. Indeed, in the 1960s, Herrnstein (1962) found that an injection of scopolamine induced motor changes in the rat, and that these same motor changes also occurred after an injection of saline solution (placebo) given after the scopolamine injection. An analogous effect is also present in humans. For example, it has long been known that placebos given after drugs are more effective than when given for the first time, that is, in the absence of previous experience with the drug they substitute (Sunshine et al, 1964; Batterman, 1966; Batterman and Lower, 1968; Laska and Sunshine, 1973). If a placebo is given for the first time, the placebo response may be present but small. If the placebo is administered after two previous administrations of an effective painkiller, the placebo analgesic response is much larger (Amanzio and Benedetti, 1999), thus indicating that the placebo effect is a learning phenomenon. Indeed, the magnitude of placebo analgesia depends on the previous experience of analgesic effects (Colloca and Benedetti, 2006).

Early in the 1930s, Tolman (1932) dissented from the view that conditioning is an automatic nonconscious event that is because of the temporal contiguity between the conditioned and the unconditioned stimulus. In the following years, conditioning was reinterpreted in cognitive terms on the basis that conditioned learning does not depend simply on the pairing of the conditioned and the unconditioned stimuli, but also on the information that is contained in the conditioned stimulus (Rescorla, 1988). In other words, conditioning would lead to the expectation that a given event will follow another event, and this occurs on the basis of the information that the conditioned stimulus provides about the unconditioned stimulus (Reiss, 1980; Rescorla, 1988; Kirsch et al, 2004). Indeed, there is now compelling evidence that the placebo effect is a learning phenomenon that may be based on different mechanisms, from unconscious conditioning to cognitive learning such as building and reinforcement of expectations.

\section{Pavlovian Conditioning}

Behavioral conditioning can be conceptualized as a placebo effect in all respects. In fact, a neutral stimulus, for example, saline or sugar, may induce a physiological response after a procedure of associative learning. This has been shown experimentally in at least two systems: the immune and the endocrine system. Some of the first compelling evidence that immunological responses can be behaviorally conditioned was obtained by a long series of experiments performed in the 1970s and 1980s. Using a taste aversion conditioning paradigm in rats, Ader and Cohen (1975) paired a flavored drinking solution (saccharin) with the immunosuppressive drug, cyclophosphamide. The rats were subsequently immunized with sheep red blood cells. After 6 days, those rats that were re-exposed to saccharin at the time of antigenic stimulation were found to have lower titers of hemagglutinating antibodies compared with conditioned animals that were not re-exposed, non-conditioned animals given saccharin, and a placebo group. Thus, saccharin was capable of mimicking the immunosuppressive action of cyclophosphamide. These effects were confirmed by other animal studies (Pacheco-Lopez et al, 2006).

Conditioned immune responses can also be obtained in humans. For example, Goebel et al (2002) provided convincing evidence that behavioral conditioning of immunosuppression is possible in humans. Repeated associations between cyclosporine A and a flavored drink induced conditioned immunosuppression in healthy male volunteers, in which the flavored drink alone produced a suppression of the immune functions, assessed using interleukin-2 (IL-2) and interferon- $\gamma$ (IFN- $\gamma$ ) mRNA expression, in vitro release of IL-2 and IFN- $\gamma$, as well as lymphocyte proliferation. It is interesting to note that the effects of the conditioned stimulus were the same as those of the specific effects of cyclosporine A. In fact, cyclosporine A binds to cyclophilins, leading to intracellular phosphatase calcineurin inhibition, which then selectively reduces the expression of some cytokines, such as IL-2 and IFN- $\gamma$, and finally results in the suppression of T-cell function. A subsequent study by the same group suggested that more than a single associative learning trial would be necessary to produce immune conditioned effects (Goebel et al, 2005), thus emphasizing the important role of learning in placebo responsiveness.

In another clinical study, Goebel et al (2009) investigated whether the effects of histamine $1(\mathrm{H} 1)$ receptor antagonist are inducible in patients suffering from house-dust mite allergy using a behavioral conditioning procedure. Throughout the association phase, patients with allergic house-dust mite rhinitis received a novel-tasting drink once daily, followed by a standard dose of the $\mathrm{H} 1$ receptor antagonist, desloratadine, on five consecutive days. During this phase, desloratadine decreased the subjective total symptom scores, attenuated the effects of the skin prick test for histamine, and reduced basophil activation ex vivo in all groups. After 9 days of drug washout, the evocation trial commenced. A first group of patients received water together with an identically looking placebo pill. A second group was re-exposed to the novel-tasting drink and received a placebo pill. A third group received water and desloratadine. During this evocation trial, the first group, which was not re-exposed to the gustatory stimulus, showed a reduction in subjective total symptom scores and skin prick test results, but no inhibition of basophil activation. In the second group, re-exposure to the noveltasting drink decreased basophil activation, the skin prick test result, and the subjective symptom score to a degree 
that was similar to the effects of desloratadine in the third group. Thus, behaviorally conditioned effects in humans are not only able to relieve subjective rhinitis symptoms, but they can also alleviate allergic skin reactions and induce changes in immune functions.

In an attempt to identify the neural substrate involved in behaviorally conditioned/placebo immunosuppression in rats, the association between saccharin as conditioned stimulus and cyclosporine $\mathrm{A}$ as unconditioned stimulus has been used to show that excitotoxic lesions of specific and discrete brain regions affect the conditioned reduction of splenocyte responsiveness and the conditioned decrease in cytokine production, such as IL-2 and IFN- $\gamma$ (PachecoLopez et al, 2005). The insular cortex is essential for both the acquisition and the evocation of these conditioned placebo responses, whereas the amygdala is likely to mediate the input of visceral information necessary at the time of acquisition. In contrast, the ventromedial hypothalamic nucleus seems to participate in the output pathway to the immune system, which is required to evoke the behaviorally conditioned immune response (Pacheco-Lopez et al, 2005, 2006).

In the endocrine system, similar effects can be found. The hypoglycemic effects of insulin can be conditioned by pairing insulin with a conditioned stimulus in animals (Alvarez-Buyalla and Carrasco-Zanini, 1960; Alvarez-Buyalla et al, 1961; Woods et al, 1968, 1969, 1972; Woods, 1972). Hypoglycemia can also be conditioned in humans. The first human observations were performed in schizophrenic patients who underwent insulin shock therapy, in which high doses of insulin are administered. When insulin was replaced with a placebo, symptoms of hypoglycemia, such as sweating, tiredness, and heart rate and blood pressure changes, occurred (Lichko, 1959). Stockhorst et al (1999, 2000) provided evidence that conditioned hypoglycemia can be obtained in humans. Although in these studies the conditioned placebo response was not large, the response pattern was consistent, and also a trend for a conditioned insulin increase could be observed.

To assess whether conditioning on one hand and expectation on the other affect hormone secretion, one study was aimed at differentiating the effects of conditioning and expectation on plasma levels of growth hormone and cortisol (Benedetti et al, 2003b). In the first experimental condition, verbal suggestions of growth hormone increase and cortisol decrease were delivered to healthy volunteers, so as to make them expect hormonal changes. These verbal instructions did not have any effect on either hormone, and in fact no plasma concentration change was detected. In the second experimental condition, sumatriptan, a serotonin $5-\mathrm{HT}_{1 \mathrm{~B} / 1 \mathrm{D}}$ receptor agonist that stimulates growth hormone and inhibits cortisol secretion, was administered for two consecutive days and then replaced by a placebo on the third day. A significant increase in growth hormone and decrease in cortisol plasma concentrations were found after placebo administration. These conditioned effects occurred regardless of the direction (increase or decrease) of the verbal suggestions received by the subjects. In other words, the placebo mimicked the sumatriptan-induced growth hormone increase, even when the subjects expected growth hormone decrease. Similarly, the placebo mimicked the sumatriptaninduced cortisol decrease, even when the subjects expected cortisol increase. It can be assumed that in this case the conditioned stimulus was represented by the act of injecting the pharmacological agent (ie, the context around the treatment). The experiment by Benedetti et al (2003b) clearly shows that sometimes it is not necessary to expect anything for a placebo response to occur. These hormonal responses represent the best examples of unconscious placebo effects, that is, placebo effects that take place in the absence of conscious cognitive processes such as the generation of expectations and beliefs.

\section{Reinforced Expectations}

In some conditions involving a conditioning procedure, placebo responses have nevertheless been found to be mediated by expectations, thus suggesting that the conditioning procedure acts by reinforcing expectations rather than generating an unconscious Pavlovian response. For example, in a classical experiment showing the role of conditioning in the placebo effect, Voudouris et al (1989, 1990) applied a neutral nonanesthetic cream (placebo) to one group of subjects who were assured that it was a local anesthetic. Not surprisingly, some of these subjects showed a placebo response after painful electrical stimulation. In a second group, the application of the same placebo cream was repeatedly associated with the surreptitious reduction in the intensity of stimulation, so as to make the subjects believe that it was a powerful painkiller. These subjects, who had experienced a 'true analgesic effect', became strong placebo responders. Voudouris et al $(1989,1990)$ concluded that conditioning is the main mechanism involved in the placebo effect.

However, with a slightly different experimental design, a cognitive component was found to contribute to the conditioning-induced placebo responses. Montgomery and Kirsch (1997) applied a protocol in which subjects were given cutaneous pain through iontophoretic stimuli. As in the studies by Voudouris et al $(1989,1990)$, they were surreptitiously given stimuli with reduced intensities in the presence of a placebo cream (conditioning procedure), but were then divided into two groups. The first group did not know about the stimulus manipulation, whereas the second was informed about the experimental design and learned that the cream was inert. There was no placebo analgesic effect in this second group, which suggests that conscious expectation is necessary for placebo analgesia. This is a very important point, as it indicates that expectation has a major role, even in the presence of a conditioning procedure.

Using a similar paradigm, Price et al (1999) applied the same placebo cream together with graded levels of heat stimulation onto three adjacent cutaneous regions of the 
forearm of subjects to elicit expectations that cream A was a strong analgesic, cream $\mathrm{B}$ a weak analgesic, and cream $\mathrm{C}$ a control agent. Immediately after these conditioning trials, subjects rated their expected pain levels during placebo test trials, in which the stimulus intensity was the same for all three regions. The conditioning trials led to graded levels of expected pain $(C>B>A)$ for the three creams, and in placebo test trials graded magnitudes of actual pain $(\mathrm{C}>\mathrm{B}>\mathrm{A})$ were reported. Thus, magnitudes of placebo analgesia could be graded across three adjacent skin areas, showing a high degree of somatotopic specificity for placebo analgesia.

The two mechanisms of conditioning and expectation can also be shown to work against each other. For example, Benedetti et al (2003b), performed for two consecutive days in one group of subjects a pharmacological preconditioning with ketorolac, a nonopioid analgesic, and then replaced the active drug with a placebo on the third day, along with verbal suggestions of analgesia. This procedure induced a strong placebo analgesic response. To see whether this placebo response was because of the pharmacological preconditioning, in a second group of subjects the same preconditioning procedure with ketorolac was carried out, but this time the placebo given on the third day was accompanied by verbal suggestions that the drug was a hyperalgesic agent. These verbal instructions were not only sufficient to block placebo analgesia completely, but were also able to produce hyperalgesia. These findings clearly show that placebo analgesia depends on expectation of pain decrease, in the absence of which even a preconditioning analgesic procedure becomes ineffective.

Although most placebo studies have at least initially focused on placebo analgesia, important contributions to the understanding of placebo mechanisms come from Parkinson's disease (PD). As occurs with pain and analgesia, the placebo effect in $\mathrm{PD}$ is usually obtained through the administration of an inert substance that the patient believes to be an effective anti-Parkinsonian drug. The assessment of the ensuing motor performance improvement is somewhat more objective than the selfreported variation of pain, as it can be evaluated by a blinded examiner with the Unified Parkinson's Disease Rating Scale (UPDRS). The manipulation of expectations has been found to affect the placebo responses in PD as well, thus indicating that expectation has an important role not only for placebo effects affecting sensory input but also motor output (Pollo et al, 2002; Benedetti et al, 2003a). For example, in the study by Benedetti et al (2003a), patients implanted for deep brain stimulation, a highly effective surgical treatment for PD, were tested for the velocity of movement of their right hand according to a double-blind experimental design in which neither the patient nor the experimenter knew whether the stimulator was turned off. The velocity of hand movement was assessed using a movement analyzer. The stimulator was turned off several times (at 4 and 2 weeks) before the test session. Each time, the velocity of movement was measured just before the stimulator was turned off and 30 min later. On the day of the experimental session, the stimulator was maintained on, but the patients were told that it had been turned off, so as to induce negative expectations of motor performance worsening (nocebo procedure). Although the stimulator was on, motor performance worsened and mimicked the worsening of the previous weeks. This nocebo bradykinesia could be prevented completely by verbal suggestions of good motor performance (placebo procedure). Therefore, as it occurs for pain, in this case also, motor performance can be modulated in two opposite directions by placebos and nocebos, and this modulation takes place on the basis of positive and negative expectations about motor performance.

To induce robust placebo responses in Parkinson patients, a pharmacological preconditioning is usually needed, for example with the anti-Parkinsonian agent, apomorphine. In a PET study using the D2-D3 dopamine receptor agonist $\left[{ }^{11} \mathrm{C}\right]$ raclopride as a radiotracer, de la Fuente-Fernandez et al (2001) obtained the first evidence that endogenous dopamine is released in the striatum after placebo administration (see above in the section on reward mechanisms and Figure 3). Their finding was later corroborated by similar results obtained with the use of sham transcranial magnetic stimulation as a placebo (Strafella et al, 2006). Similar strong placebo responses were obtained through apomorphine preconditioning just before intraoperative recording of single neuron activity in the subthalamic nucleus. These patients showed a significant decrease in neuronal firing rate associated with a shift from a bursting to a non-bursting pattern of discharge (Benedetti et al, 2004). These changes in the subthalamic nucleus were found to be associated with changes in neuronal activity in the substantia nigra pars reticulata and in the thalamus, which suggest that part of the basal ganglia and thalamic circuit is affected by placebos, as shown in Figure 3 (Benedetti et al, 2009). In addition, these neurophysiological changes were found to be related to both muscle rigidity reduction and subjective reports of wellbeing. By considering the important role of expectations in placebo responsiveness in Parkinson patients and the robust placebo responses obtained through previous apomorphine conditioning, these data suggest that reinforcement of expectations, that is, cognitive learning, is involved.

The relevance of motor placebo responses is not confined to damaged systems as in $\mathrm{PD}$, but it can be extended to intact motor systems. In a recent study, the effects of ergogenic placebos on the quadriceps muscle, which is responsible for the extension of the leg relative to the thigh, were studied (Pollo et al, 2008). A placebo, which the subjects believed to be caffeine at high doses, was administered twice in two different sessions, and each time the weight to be lifted with the quadriceps was reduced surreptitiously so as to make the subjects believe that the 'ergogenic agent' was effective. After this conditioning procedure, the load was restored to the original weight, and 


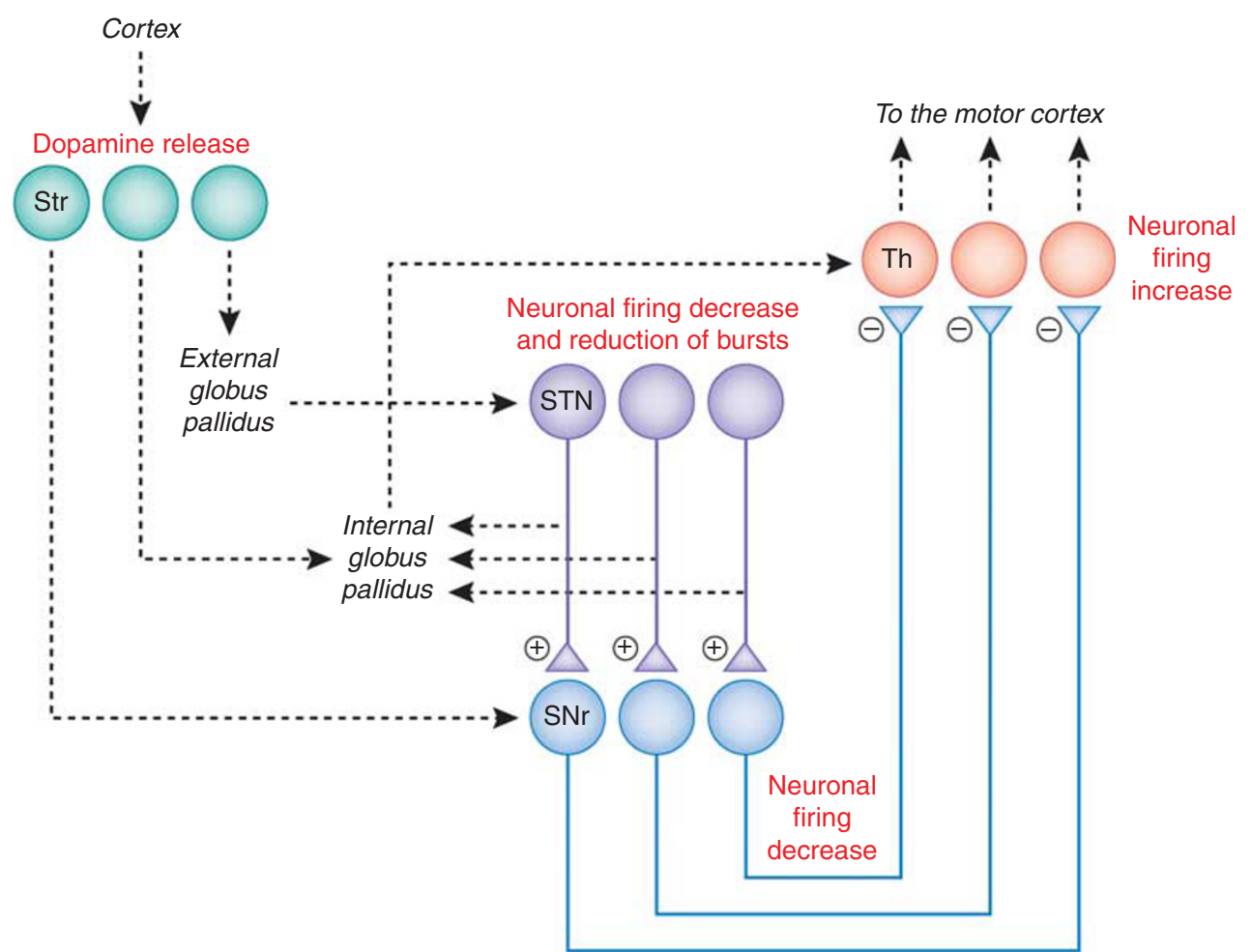

Figure 3. Neural circuit involved in the placebo response in Parkinson's disease. The changes observed in this circuit have been obtained after pharmacological preconditioning with apomorhine, which suggests that learning is important for these changes to occur. A release of dopamine in both the ventral and dorsal striatum (Str) occurs. The neurons of the subthalamic nucleus (STN) and substantia nigra pars reticulata (SNr) have been found to decrease their firing rate, whereas the neurons in the ventral anterior and anterior ventral lateral thalamus (Th) have been found to increase their discharge. The nuclei in italics and the broken lines indicate the part of the circuit that has not been studied. Although the release of dopamine in Str and the neuronal changes in STN, SNr, and Th were found in different studies (de la Fuente-Fernandez et al, 2001, 2002 and Benedetti et al, 2004,2009 , respectively), the neuronal changes in STN, SNr, and Th are likely to derive from dopamine release in Str.

both muscle work and fatigue assessed after placebo administration. A clear placebo effect occurred, with a significant increase in muscle work and decrease in muscle fatigue. These findings suggest the possible modulation by a placebo of a central neural governor of fatigue, which normally acts by pacing the muscles and setting a limit to keep them back from total exhaustion. This central governor would be offset by the placebo, allowing muscular performance to be pushed a little further.

\section{Social Learning}

Social learning is a form of learning, in which individuals in a society learn from one another by observation and imitation. Placebo effects may involve social learning as well (Bootzin and Caspi, 2002), and expectations of future outcomes may have a major effect on social learning. Colloca and Benedetti (2009) compared placebo analgesia induced through social observation with first-hand experience through a typical conditioning procedure and with verbal suggestion alone. In the social observation condition, subjects underwent painful stimuli and placebo treatment after they had observed a demonstrator (actually a simulator) showing analgesic effect when the painful stimuli were paired to a green light. In the conditioning experimental condition, subjects were conditioned according to a classical conditioning procedure, in which a green light was associated with the surreptitious reduction in stimulus intensity, so as to make them believe that the treatment worked. In the verbal suggestion condition, subjects received painful stimuli and were verbally instructed to expect a benefit from a green light. It was found that observing the beneficial effects in the demonstrator induced substantial placebo analgesic responses that were positively correlated with empathy scores. Moreover, observational social learning produced placebo responses that were similar to those induced by directly experiencing the benefit through the conditioning procedure, whereas verbal suggestions alone produced significantly smaller effects. Thus, social observation is as powerful as conditioning in producing substantial placebo responses.

\section{GENETIC VARIANTS OF PLACEBO RESPONSIVENESS}

A central issue in placebo research is whether an individual in whom a placebo works possesses one or more specific characteristics, which can reliably identify him a priori as a 'placebo responder', with important implications for both 
clinical trials design and personalized therapy optimization. Results have so far been rather inconclusive, with demographic, psychosocial, personality, and behavioral variables all proposed to have a role, but all inconsistently present across different trials (Kaptchuk et al, 2008). Recently, however, some genetic variants have been found that are particularly responsive to placebo treatment, thereby emphasizing the possible role of genetic factors. It is worth noting, though, that only two genetic studies are so far available, and thus they need confirmation and further research.

\section{Genetic Variants in Social Anxiety}

There is some experimental evidence that some genetic variants related to serotonin affect placebo responses in psychiatric disorders (Rausch et al, 2002; Furmark et al, 2008). For example, Furmark et al (2008) used functional neuroimaging to examine neural correlates of anxiety reduction resulting from placebo treatment in patients with social anxiety disorder. Brain activity was assessed during a stressful public speaking task using PET before and after an 8 -week treatment period. The patients were genotyped with respect to the serotonin transporter-linked polymorphic region (5-HTTLPR) and the G-703T polymorphism in the tryptophan hydroxylase-2 (TPH2) gene promoter. It was found that the reduced stress-related activity in the amygdala that accompanied the placebo response could be observed only in subjects who were homozygous for the long allele of the 5-HTTLPR or the G variant of the TPH2 G-703T polymorphism, but not in carriers of short or $\mathrm{T}$ alleles. In addition, the TPH2 polymorphism was a significant predictor of clinical placebo response, with homozygosity for the $\mathrm{G}$ allele being associated with greater improvement in anxiety symptoms.

\section{Genetic Variants in Depression}

On the basis of the action of placebos on monoamines of the reward circuitry and because monoaminergic signaling is under strong genetic control, Leuchter et al (2009) examined the relationship between placebo responses and polymorphisms in genes encoding the catabolic enzymes catechol-O-methyltransferase and monoamine oxidase A in subjects with major depressive disorder. Subjects with monoamine oxidase A G/T polymorphisms (rs6323) coding for the highest activity form of the enzyme ( $\mathrm{G}$ or $\mathrm{G} / \mathrm{G}$ ) had a significantly lower magnitude of placebo response than those with other genotypes. Subjects with ValMet catechol$O$-methyltransferase polymorphisms coding for a loweractivity form of the enzyme ( 2 Met alleles) showed a statistical trend toward a lower magnitude of placebo response.

These data support the possible role of genes in some types of placebo responses; for example, a genetically controlled serotoninergic modulation of amygdala activity, which is linked to placebo-induced anxiety relief, and a genetically controlled monoaminergic tone, which is related to degree of placebo responsiveness in major depressive disorder.

\section{NO PREFRONTAL CONTROL, NO PLACEBO RESPONSE}

\section{Prefrontal Degeneration in Alzheimer's Disease}

One of the features of Alzheimer's disease (AD) is the impairment of prefrontal executive control. Specific aspects of this executive control can be tracked down to definite prefrontal areas, for example, abstract reasoning to dorsolateral frontal regions and inhibitory control to orbital and medial frontal areas (Berman et al, 1995; Nagahama et al, 1996; Rolls et al, 1996; Konishi et al, 1998, 1999a, b). Interestingly, the very same regions have been found to be activated by placebo-induced expectation of benefit, such as pain reduction (Petrovic et al, 2002; Wager et al, 2004; Zubieta et al, 2005). In AD, the frontal lobes are severely affected, with marked neuronal degeneration in the dorsolateral prefrontal cortex, the orbitofrontal cortex, and the anterior cingulate cortex (Thompson et al, 2003). It is therefore reasonable to also expect in these patients a loss of placebo responsiveness.

Benedetti et al (2006b) studied Alzheimer patients at the initial stage of the disease and after 1 year to see whether the placebo component of the therapy (an ever-present part of the drug effect that makes the overall outcome greater than that produced purely by the intrinsic principle) was affected by the disease. In this study, the placebo component of the analgesic therapy was correlated with both cognitive status, as assessed using Frontal Assessment Battery (FAB) test, and functional connectivity among different brain regions, as assessed using electroencephalographic connectivity analysis. In fact, it was found that Alzheimer's patients with reduced FAB scores showed reduced placebo component of an analgesic treatment. In addition, the disruption of the placebo component occurred just when reduced connectivity of the prefrontal lobes with the rest of the brain was present. The loss of these placebo-related mechanisms reduced the overall effectiveness of the treatment, and indeed a dose increase was necessary to make up for this loss to produce adequate analgesia.

This was the first study showing that a disruption of the placebo-psychological component of a treatment may occur in a clinical condition that affects the brain, specifically the prefrontal lobes, and that the damage of these prefrontal expectation-related mechanisms makes an analgesic treatment less effective. According to this view, the impairment of prefrontal connectivity would reduce the communication between the prefrontal lobes and the rest of the brain, so that no placebo and expectation mechanisms would be triggered.

There are at least two important aspects that emerge from the disruption of placebo and expectation mechanisms in $\mathrm{AD}$. First, the reduced efficacy of the open analgesic 
treatment underscores the need of considering a possible revision of some therapies in Alzheimer patients to compensate for the loss of placebo- and expectation-related mechanisms. Second, the neuroanatomical localization of placebo- and expectation-related mechanisms should alert us to the potential disruption of placebo mechanisms in all those conditions in which the prefrontal lobes are involved, for example, other forms of dementia such as vascular and frontotemporal dementia, or any prefrontal cortex lesion.

\section{Blockade of Prefrontal Opioid Neurotransmission}

As discussed in the previous section, a functional disconnection of the prefrontal lobes from the rest of the brain is associated with a loss of placebo responsiveness. Interestingly, in recent years this notion has been supported by the deactivation of the prefrontal cortex in the experimental setting. On the basis of previous experiments on the blockade of placebo analgesia by the opioid antagonist naloxone (see, eg, Amanzio and Benedetti, 1999), Eippert et al (2009a) conducted a study to investigate the location of naloxone action in the brain. By combining naloxone administration with $\mathrm{fMRI}$, these researchers found that naloxone reduced behavioral placebo effects as well as placebo-induced responses in pain-modulatory cortical structures, such as the dorsolateral prefrontal cortex and the rostral anterior cingulate cortex. In a brainstem-specific analysis, a similar naloxone modulation of placebo-induced responses in key structures of the descending pain control system, including the hypothalamus, the periaqueductal gray, and the rostral ventromedial medulla, was also found. Most importantly, naloxone abolished the increase in coupling between the rostral anterior cingulate cortex and the periaqueductal gray that was induced by the placebo. Therefore, as it occurs for prefrontal degeneration in $\mathrm{AD}$, placebo analgesic responses are disrupted by the pharmacological blockade of prefrontal opioidergic functioning in the experimental setting.

\section{Prefrontal Inactivation by Transcranial Magnetic Stimulation}

Prefrontal degeneration in Alzheimer's disease and pharmacological blockade of prefrontal opioidergic transmission are not the only conditions in which placebo responses are disrupted. Recently, repetitive transcranial magnetic stimulation (rTMS) has been used to inactivate the prefrontal cortex, particularly the dorsolateral prefrontal cortex, during a placebo analgesic response (Krummenacher et al, 2010). rTMS is known to depress cortical excitability of the targeted cortical region; thus, it represents an excellent experimental approach to investigate how loss of prefrontal control may affect complex cognitive functions, such as expectation-induced placebo responses. In a heat pain paradigm, Krummenacher et al (2010) used noninvasive, low-frequency rTMS to transiently disrupt the left and right dorsolateral prefrontal cortex function or used the transcranial stimulation device itself as a placebo, before applying an expectation-induced placebo analgesia procedure. It was found that, whereas placebo significantly increased pain threshold and pain tolerance, rTMS completely blocked placebo analgesia.

Therefore, the inactivation of prefrontal regions by transcranial magnetic stimulation has the same effects as those induced by pharmacological blockade or prefrontal degeneration in Alzheimer's disease. On the basis of all these studies, a normal functioning of prefrontal areas, as well as of the descending pain modulating network with which it is connected (Basbaum and Fields, 1984), seems to be critical for placebo responsiveness. In the presence of a loss of prefrontal control, we also witness a loss of placebo response (Benedetti, 2010).

\section{CLINICAL IMPLICATIONS}

On the basis of the neurobiological findings presented in this review, it is clear that whenever a medical treatment is carried out, a complex cascade of biochemical events is activated by several social stimuli. Such events will inevitably contribute to the responses observed with drug administration. In other words, drugs are not administered into a vacuum but rather into a complex biochemical environment that varies according to the patient's cognitive/affective state and to previous exposure to other pharmacological agents. For example, as shown in Figure $4 \mathrm{a}$, when a syringe (or any other stimulus related to the therapeutic act) is presented, the patient starts expecting a therapeutic benefit, so that his or her brain starts activating different biochemical pathways, such as opioids, CCK and dopamine (step 1). In step 2 the drug is injected through the syringe, and its effect, for example, analgesia, can be because of its own pharmacodynamic action and/or an interference with any of these expectationactivated biochemical mechanisms (step 3). Is this analgesic effect mediated by the pharmacodynamic action of the drug? Or rather is it mediated by its interaction with expectation/placebo mechanisms? The question sounds paradoxical and, indeed, the answer is not easy. As we have no a priori knowledge of which pharmacological agents act on expectation/placebo mechanisms - and indeed almost all drugs might interfere with these mechanisms - we will never know where the observed effect comes from exactly. It might stem from the action of the drug upon placebo mechanisms or, alternatively, it might derive from its specific pharmacodynamic action. This has been called 'the uncertainty principle' (Colloca and Benedetti, 2005). It asserts that it is impossible to assess with sureness the origin of the action of a pharmacological agent, as its pharmacodynamic action is perturbed by the act of administering it. In other words, when a drug is given, the very act of administering (ie, the psychosocial context) may perturb the system and change the response to the drug. 

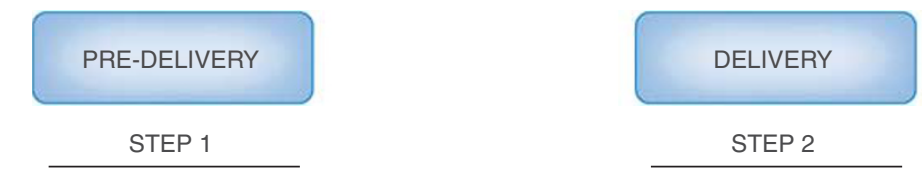

a

Possible interaction between drug and placebo/expectation effect
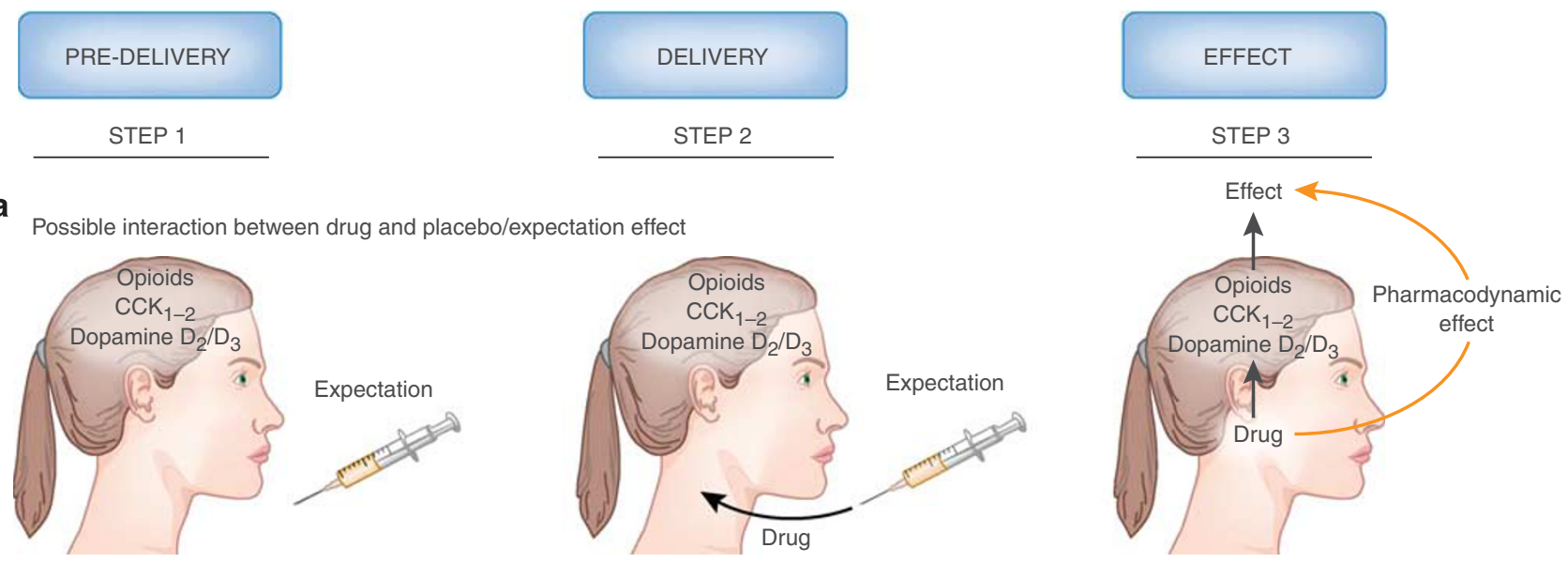

b

Eliminating placebo/expectation- activated mechanisms
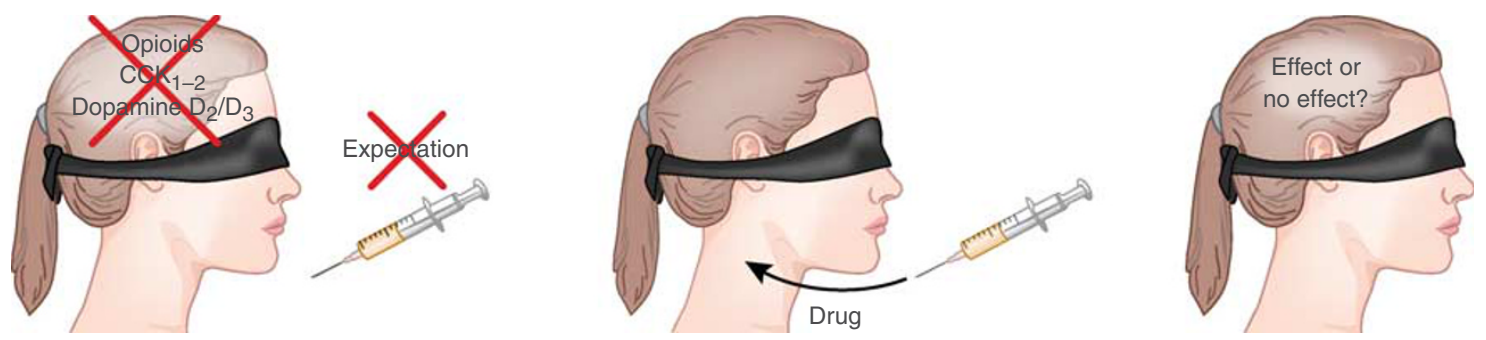

Figure 4. Interference between placebo/expectation effects and drug action. (a) When a syringe, or any other medical device, is presented, the patient's brain starts activating placebo/expectation mechanisms, such as opioid, dopamine, and cholecystokinin (CCK) release (step 1). Then the drug is injected (step 2). Its effect may be because of its own pharmacodynamic action and/or of an interference with expectation-activated mechanisms (step 3). In this situation, there is no way to say which of these two mechanisms takes place. (b) If placebo/expectation mechanisms are eliminated using a hidden (unexpected) administration, any observed effect is likely to be because of the specific pharmacodynamic action of the drug itself, for any expectation-related mechanism is no longer present.

There is a way to overcome the interference between drugs and placebo/expectation effects. This can be done by, so to speak, 'silencing' the expectation mechanisms, for example, by eliminating the placebo (psychosocial) component by making the patient unaware that a medical therapy is being carried out (Figure $4 \mathrm{~b}$ ), and then analyzing the pharmacodynamic effect of the treatment, free of any psychological contamination (Levine et al, 1981; Levine and Gordon, 1984; Amanzio et al, 2001; Benedetti et al, 2003b; Colloca et al, 2004). To do this, drugs are delivered through hidden infusions by machines. Such infusions can be administered using computer-controlled infusion pumps that are preprogrammed to dispense drugs at a desired time. The crucial factor is that the patients do not know that the drug is being injected, so they ought not have expectations of a therapeutic response. This contrasts with open administration, used in routine medical practice, in which drugs are given overtly and the patients expect a clinical benefit. Therefore, an open injection of a drug provides an expected treatment, whereas a hidden injection represents an unexpected therapy.

If the drug of Figure $4 \mathrm{a}$ is really effective and has only specific pharmacodynamic action, there should be no difference between its open (Figure 4a) and hidden (Figure 4b) administration, for it does not act on expectation-activated neurotransmitters. In contrast, if the drug of Figure 4a has no specific pharmacodynamic action and it only interferes with expectation-activated neurotransmitters, its hidden administration (Figure 4b) should abolish the observed effect completely. Indeed, a trial conducted by Benedetti et al (1995) showed that a CCK antagonist induced stronger analgesia than a placebo, suggesting that it was a good analgesic. However, this conclusion proved to be erroneous because a hidden injection of the same CCK antagonist was totally ineffective, showing that it had no intrinsic analgesic pharmacodynamic action, but instead, it enhanced placebo-activated release of endogenous opioids. Therefore, an analgesic that is tested according to the classical methodology of clinical trials can potentially produce a better response than a placebo, even though it lacks analgesic properties. A future challenge will be to better understand and to answer the question: should we consider a drug that acts upon expectation-activated mechanisms effective or not? Or, in other words, in this trial (Benedetti et al, 1995), should we consider the CCK antagonist a painkiller or not? 


\section{FUTURE RESEARCH DIRECTIONS}

Despite the recent explosion of neurobiological placebo research and the recent findings that help us better understand both human biology and clinical practice, several issues need further clarifications and many questions still remain unanswered. First of all we need to know where, when, and how placebos work across different diseases and therapeutic interventions, and it would also be interesting to test the effects of pharmacological conditioning for different classes of drugs, such as immunosuppressive and hormone-stimulating agents. In addition, a better understanding of the contribution of expectation and conditioning in different types of placebo responses is in order, and this would surely help identify the social, psychological, and neurobiological determinants of the different placebo effects. A last unresolved issue is why some subjects respond to placebos, whereas other subjects do not, a critical point that is likely to be clarified by pursuing further research into both learning and genetic mechanisms.

\section{ACKNOWLEDGEMENTS}

This work was supported by grants from Regione Piemonte and Compagnia di San Paolo (Turin, Italy) and from the Volkswagen Foundation (Hannover, Germany).

\section{DISCLOSURE}

The authors declare no conflict of interest.

\section{REFERENCES}

Ader R, Cohen N (1975). Behaviourally conditioned immunosuppression. Psychosom Med 37: 333-340.

Alvarez-Buyalla R, Carrasco-Zanini J (1960). A conditioned reflex which reproduces the hypoglycemic effect of insulin. Acta Physiol Lat Am 10: 153-158.

Alvarez-Buyalla R, Segura ET, Alvarez-Buyalla ER (1961). Participation of the hypophysis in the conditioned reflex which reproduces the hypoglycemic effect of insulin. Acta Physiol Lat Am 11: 113-119.

Amanzio M, Benedetti F (1999). Neuropharmacological dissection of placebo analgesia: expectation-activated opioid systems versus conditioning-activated specific subsystems. J Neurosci 19: 484-494.

Amanzio M, Pollo A, Maggi G, Benedetti F (2001). Response variability to analgesics: a role for non-specific activation of endogenous opioids. Pain 90: 205-215.

Andre J, Zeau B, Pohl M, Cesselin F, Benoliel JJ, Becker C (2005). Involvement of cholecystokininergic system in anxiety-induced hyperalgesia in male rats: behavioral and biochemilac studies. J Neurosci 25: 7896-7904.

Bandura A (1997). Self-Efficacy: The Exercise of Control. Cambridge University Press: New York

Basbaum Al, Fields HL (1984). Endogenous pain control systems: brainstem spinal pathways and endorphin circuitry. Ann Rev Neurosci 7: 309-338.

Batterman RC (1966). Persistence of responsiveness with placebo therapy following an effective drug trial. J New Drugs 6: 137-141.

Batterman RC, Lower WR (1968). Placebo responsiveness-influence of previous therapy. Curr Therap Res 10: 136-143.

Benedetti F (1996). The opposite effects of the opiate antagonist naloxone and the cholecystokinin antagonist proglumide on placebo analgesia. Pain 64: 535-543.

Benedetti $F$ (2008a). Mechanisms of placebo and placebo-related effects across diseases and treatments. Annu Rev Pharmacol Toxicol 48: 33-60.

Benedetti F (2008b). Placebo Effects: Understanding the Mechanisms in Health and Disease. Oxford University Press: Oxford. This book describes the neurobiological mechanisms of different placebo effects and placebo- related effects across a variety of medical conditions, therapeutic interventions, systems and apparatuses.

Benedetti F (2010). No prefrontal control, no placebo response. Pain 148: 357-358. Benedetti F, Amanzio M (1997). The neurobiology of placebo analgesia: from endogenous opioids to cholecystokinin. Prog Neurobiol 52: 109-125.

Benedetti F, Amanzio M, Casadio C, Oliaro A, Maggi G (1997). Blockade of nocebo hyperalgesia by the cholecystokinin antagonist proglumide. Pain 71: 135-140.

Benedetti F, Amanzio M, Maggi G (1995). Potentiation of placebo analgesia by proglumide. Lancet 346: 1231.

Benedetti F, Amanzio M, Vighetti S, Asteggiano G (2006a). The biochemical and neuroendocrine bases of the hyperalgesic nocebo effect. J Neurosci 26: 12014-12022.

Benedetti F, Arduino C, Costa S, Vighetti S, Tarenzi L, Rainero I et al (2006b). Loss of expectation-related mechanisms in Alzheimer's disease makes analgesic therapies less effective. Pain 121: 133-144. The first evidence that placebo responses are disrupted when there is an impairment of the prefrontal regions of the brain.

Benedetti F, Colloca L, Torre E, Lanotte M, Melcarne A, Pesare M et al (2004). Placebo-responsive Parkinson patients show decreased activity in single neurons of subthalamic nucleus. Nat Neurosci 7: 587-588. This paper provides the first evidence of a placebo effect at the single-neuron level, showing that a placebo procedure affects specific neuronal populations.

Benedetti F, Lanotte M, Colloca L, Ducati A, Zibetti M, Lopiano L (2009). Electrophysiological properties of thalamic, subthalamic and nigral neurons during the anti-parkinsonian placebo response. J Physio/ 587: 3869-3883.

Benedetti F, Maggi G, Lopiano L, Colloca L (2007). When words are painful-unraveling the mechanisms of the nocebo effect. Neuroscience 147: 260-271.

Benedetti F, Maggi G, Lopiano L, Lanotte M, Rainero I, Vighetti S et al (2003a). Open versus hidden medical treatments: the patient's knowledge about a therapy affects the therapy outcome. Prev Treat 6. Available at http:// psycnet.apa.org/index.cfm?fa=search.displayRecord\&uid=2003-07872-001.

Benedetti F, Mayberg HS, Wager TD, Stohler CS, Zubieta JK (2005). Neurobiological mechanisms of the placebo effect. J Neurosci 25: 10390-10402.

Benedetti F, Pollo A, Lopiano L, Lanotte M, Vighetti S, Rainero I (2003b). Conscious expectation and unconscious conditioning in analgesic, motor and hormonal placebo-nocebo responses. J Neurosci 23: 4315-4323.

Berman KF, Ostrem JL, Randolph C, Gold J, Goldberg TE, Coppola R et al (1995). Physiological activation of a cortical network during performance of the Wisconsin Card Sorting Test: a positron emission tomography study. Neuropsychologia 33: 1027-1046.

Bootzin RR (1985). The role of expectancy in behavior change. In: White L, Tursky B, Schwartz GE (eds). Placebo: Theory, Research, and Mechanisms. Guilford Press: New York. pp 196-210.

Bootzin RR, Caspi O (2002). Explanatory mechanisms for placebo effects: cognition, personality and social learning. In: HA Guess, A Kleinman, JW Kusek, LW Engel (eds). The Science of the Placebo: Toward an Interdisciplinary Research Agenda. BMJ Books: London, UK. pp 108-132.

Chua P, Krams M, Toni I, Passingham R, Dolan R (1999). A functional anatomy of anticipatory anxiety. Neuroimage 9: 563-571.

Colloca L, Benedetti F (2005). Placebos and painkillers: is mind as real as matter? Nat Rev Neurosci 6: 545-552.

Colloca L, Benedetti F (2006). How prior experience shapes placebo analgesia. Pain 124: 126-133.

Colloca L, Benedetti F (2007). Nocebo hyperalgesia: how anxiety is turned into pain. Curr Opin Anaesthesiol 20: 435-439.

Colloca L, Benedetti F (2009). Placebo analgesia induced by social observational learning. Pain 144: 28-34.

Colloca L, Lopiano L, Lanotte M, Benedetti F (2004). Overt versus covert treatment for pain, anxiety and Parkinson's disease. Lancet Neurol 3: 679-684.

Colloca L, Sigaudo M, Benedetti F (2008). The role of learning in nocebo and placebo effects. Pain 136: 211-218.

de la Fuente-Fernandez R, Phillips AF, Zamburlini M, Sossi V, Calne DB, Ruth TJ et al (2002). Dopamine release in human ventral striatum and expectation of reward. Behav Brain Res 96: 393-402.

de la Fuente-Fernandez R, Ruth TJ, Sossi V, Schulzer M, Calne DB, Stoessl AJ (2001). Expectation and dopamine release: mechanisms of the placebo effect in Parkinson's disease. Science 293: 1164-1166. This is the first imaging study of the placebo effect, showing a dopamine release in Parkinson's disease.

Eippert F, Bingel U, Schoell ED, Yacubian J, Klinger R, Lorenz J et al (2009a). Activation of the opioidergic descending pain control system underlies placebo analgesia. Neuron 63: 533-543.

Eippert F, Finsterbusch J, Bingel U, Büchel C (2009b). Direct evidence for spinal cord involvement in placebo analgesia. Science 326: 404. In this paper, the placebo analgesic response is also found to involve the spinal cord, thus 
showing that placebos may affect early processing of nociceptive information.

Enck P, Benedetti F, Schedlowski M (2008). New insights into the placebo and nocebo responses. Neuron 59: 195-206. This comprehensive review summarizes the current neurobiological models of both placebo and nocebo phenomena.

Evans FJ (1977). The placebo control of pain: a paradigm for investigating non-specific effects in psychotherapy. In: JP Brady, J Mendels, WR Reiger, MT Orne (eds). Psychiatry: Areas of Promise and Advancement. Plenum Press: New York. pp 249-271.

Finniss DG, Kaptchuk TJ, Miller F, Benedetti F (2010). Biological, clinical, and ethical advances of placebo effects. Lancet 375: 686-695.

Flor H, Grüsser SM (1999). Conditioned stress-induced analgesia in humans. Eur J Pain 3: 317-324.

Frank JD (1971). Therapeutic factors in psychotherapy. Am J Psychother 25: 350-361.

Furmark T, Appel L, Henningsson S, Ahs F, Faria V, Linnman C et al (2008). A link between serotonin-related gene polymorphisms, amygdala activity, and placeboinduced relief from social anxiety. J Neurosci 28: 13066-13074. This study shows, for the first time, evidence of a link between genetically controlled serotonergic modulation of amygdala activity and placebo-induced anxiety relief.

Goebel MU, Hubell D, Kou W, Janssen OE, Katsarava Z, Limmroth V et al (2005). Behavioural conditioning with interferon beta-1a in humans. Physiol Behav 84: 807-814.

Goebel MU, Meykadeh N, Kou W, Schedlowski M, Hengge UR (2009). Behavioural conditioning of antihistamine effects in patients with allergic rhinitis. Psychother Psychosom 77: 227-234.

Goebel MU, Trebst AE, Steiner J, Xie YF, Exton MS, Frede S et al (2002). Behavioural conditioning of immunosuppression is possible in humans. FASEB J 16: 1869-1873. This paper clearly shows that behavioral conditioning is possible in the human immune system, and indicates that placebo immune responses are mediated by classical conditioning in humans

Hebb ALO, Poulin J-F, Roach SP, Zacharko RM, Drolet G (2005). Cholecystokinin and endogenous opioid peptides: interactive influence on pain, cognition, and emotion. Prog Neuropsychopharmacol Biol Psychiatry 29: 1225-1238.

Heinricher MM, McGaraughty S, Tortorici V (2001). Circuitry underlying antiopioid actions of cholecystokinin within the rostral ventromedial medulla. J Neurophysiol 85: 280-286.

Heinricher MM, Neubert MJ (2004). Neural basis for the hyperalgesic action of cholecystokinin in the rostral ventromedial medulla. J Neurophysiol 92: 1982-1989.

Herrnstein RJ (1962). Placebo effect in the rat. Science 138: 677-678.

Hsieh JC, Stone-Elander S, Ingvar M (1999). Anticipatory coping of pain expressed in the human anterior cingulate cortex: a positron emission tomography study. Neurosci Lett 262: 61-64.

Kalivas PW, Churchill L, Romanides A (1999). Involvement of the pallidal-thalamocortical circuit in adaptive behavior. Ann NY Acad Sci 877: $64-70$

Kaptchuk T, Kelley JM, Deykin A, Wayne PM, Lasagna LC, Epstein IO et al (2008). Do 'placebo responders' exist? Contemp Clin Trials 29: 587-595.

Keltner JR, Furst A, Fan C, Redfern R, Inglis B, Fields HL (2006). Isolating the modulatory effect of expectation on pain transmission: a functional magnetic imaging study. J Neurosci 26: 4437-4443.

Kirsch I (1999). How Expectancies Shape Experience. American Psychological Association: Washington DC.

Kirsch I, Sapirstein G (1998). Listening to Prozac but hearing placebo: a metaanalysis of antidepressant medication. Prev Treat 1 Article 0002a (originally published online 1 February 2003, at http://journals.apa.org/prevention/ volume1/pre0010002a.html).

Kirsch I, Lynn SJ, Vigorito M, Miller RR (2004). The role of cognition in classical and operant conditioning. J Clin Psychol 60: 369-392.

Kong J, Gollub RL, Polich G, Kirsch I, LaViolette P, Vangel M et al (2008). A functional magnetic resonance imaging study on the neural mechanisms of hyperalgesic nocebo effect. J Neurosci 28: 13354-13362.

Konishi S, Kawazu M, Uchida I, Kikyo H, Asakura I, Miyashita Y (1999a). Contribution of working memory to transient activation in human inferior prefrontal cortex during performance of the Wisconsin Card Sorting Test. Cereb Cortex 9: 745-753.

Konishi S, Nakajima K, Uchida I, Kameyama M, Nakahara K, Sekihara K et al (1998). Transient activation of inferior prefrontal cortex during cognitive set shifting. Nat Neurosci 1: 80-84.

Konishi S, Nakajima K, Uchida I, Kikyo H, Kameyama M, Miyashita Y (1999b). Common inhibitory mechanism in human inferior prefrontal cortex revealed by event-related functional MRI. Brain 122. 981-991.
Koyama T, McHaffie JG, Laurienti PJ, Coghill RC (2005). The subjective experience of pain: where expectations became reality. Proc Nat Acad Sci USA 102: 12950-12955.

Koyama T, Tanaka YZ, Mikami A (1998). Nociceptive neurons in the macaque anterior cingulated activate during anticipation of pain. NeuroReport 9: 2663-2667.

Krummenacher P, Candia V, Folkers G, Schedlowski M, Schönbächler G (2010). Prefrontal cortex modulates placebo analgesia. Pain 148: 368-374. This study shows that the inactivation of the dorsolateral prefrontal cortex prevents placebo analgesia.

Laska E, Sunshine A (1973). Anticipation of analgesia: a placebo effect. Headache 13: $1-11$

Last JM (1983). A Dictionary of Epidemiology. Oxford University Press: New York.

Leuchter AF, McCracken JT, Hunter AM, Cook IA, Alpert JE (2009). Monoamine oxidase a and catechol-o-methyltransferase functional polymorphisms and the placebo response in major depressive disorder. J Clin Psychopharmacol 29: 372-377.

Levine JD, Gordon NC (1984). Influence of the method of drug administration on analgesic response. Nature 312: 77-94.

Levine JD, Gordon NC, Fields HL (1978). The mechanisms of placebo analgesia. Lancet 2: 654-657.

Levine JD, Gordon NC, Smith R, Fields HL (1981). Analgesic responses to morphine and placebo in individuals with postoperative pain. Pain 10: 379-389.

Lichko AE (1959). Conditioned reflex hypoglycemia in man. Pavlov J High Nerv Activity 9: 731-737.

Lorenz J, Hauck M, Paur RC, Nakamura Y, Zimmerman R, Bromm B et al (2005). Cortical correlates of false expectations during pain intensity judgments-a possible manifestation of placebo/nocebo cognitions. Brain Behav Immun 19: 283-295.

Mayberg HS, Silva JA, Brannan SK, Tekell JL, Mahurin RK, McGinnis S et al (2002). The functional neuroanatomy of the placebo. Am J Psychiatry 159: 728-737.

McGlashan TH, Evans FJ, Orne MT (1969). The nature of hypnotic analgesia and placebo response to experimental pain. Psychosom Med 31: 227-246.

Mitchell JM, Lowe D, Fields HL (1998). The contribution of the rostral ventromedial medulla to the antinociceptive effects of systemic morphine in restrained and unrestrained rats. Neuroscience 87: 123-133.

Moerman DE (2002). Meaning, Medicine and the Placebo Effect. Cambridge University Press: Cambridge.

Mogenson GJ, Yang CA (1991). The contribution of basal forebrain to limbic-motor integration and the mediation of motivation to action. Adv Exp Med Biol 295: 267-290.

Montgomery GH, Kirsch I (1997). Classical conditioning and the placebo effect. Pain 72: 107-113

Nagahama Y, Fukuyama H, Yamauchi H (1996). Cerebral activation during performance of a card-sorting test. Brain 119: 1667-1675.

Noble F, Wank SA, Crawley JN, Bradwejn J, Seroogy KB, Hamon M et al (1999). International Union of Pharmacology. XXI. Structure, distribution, and functions of cholecystokinin receptors. Pharmacol Rev 51: 745-781.

Pacheco-Lopez G, Engler H, Niemi MB, Schedlowski M (2006). Expectations and associations that heal: immunomodulatory placebo effects and its neurobiology. Brain Behav Immun 20: 430-446. This article reviews the state of the art of immune placebo responses in both humans and animals.

Pacheco-Lopez G, Niemi MB, Kou W, Harting M, Fandrey J, Schedlowski M (2005). Neural substrates for behaviourally conditioned immunosuppression in the rat. Neurosci 25: 2330-2337.

Petrovic P, Dietrich T, Fransson P, Andersson J, Carlsson K (2005). Placebo in emotional processing-induced expectations of anxiety relief activate a generalized modulatory network. Neuron 46: 957-969.

Petrovic P, Kalso E, Petersson KM, Ingvar M (2002). Placebo and opioid analgesia-imaging a shared neuronal network. Science 295: 1737-1740. This positron emission tomography study shows similar brain responses to opioids and to placebos, which suggest that they share a common neural network

Ploghaus A, Narain C, Beckmann CF, Clare S, Bantick S, Wise R et al (2001). Exacerbation of pain by anxiety is associated with activity in a hippocampal network. J Neurosci 21: 9896-9903.

Ploghaus A, Tracey I, Gati JS, Clare S, Menon RS, Matthews PM et al (1999). Dissociating pain from its anticipation in the human brain. Science 64 : 1979-1981.

Pollo A, Carlino E, Benedetti F (2008). The top-down influence of ergogenic placebos on muscle work and fatigue. Eur J Neurosci 28: 379-388.

Pollo A, Torre E, Lopiano L, Rizzone M, Lanotte M, Cavanna A et al (2002). Expectation modulates the response to subthalamic nucleus stimulation in Parkinsonian patients. NeuroReport 13: 1383-1386. 
Porro CA, Baraldi P, Pagnoni G, Serafini M, Facchin P, Maieron M et al (2002). Does anticipation of pain affect cortical nociceptive systems? J Neurosci 22: 3206-3214.

Porro CA, Cettolo V, Francescato MP, Baraldi P (2003). Functional activity mapping of the mesial hemispheric wall during anticipation of pain. Neuroimage 19: 1738-1747.

Price DD, Finniss DG, Benedetti F (2008). A comprehensive review of the placebo effect: recent advances and current thought. Annu Rev Psychol 59: 565-590.

Price DD, Milling LS, Kirsch I, Duff A, Montgomery GH, Nicholls SS (1999). An analysis of factors that contribute to the magnitude of placebo analgesia in an experimental paradigm. Pain 83: 147-156.

Rausch JL, Johnson ME, Fei YJ, Li JQ, Shendarkar N, Hobby HM et al (2002). Initial conditions of serotonin transporter kinetics and genotype: influence on SSRI treatment trial outcome. Biol Psychiatry 51: 723-732.

Reiss S (1980). Pavlovian conditioning and human fear: an expectancy model. Behav Ther 11: 380-396.

Rescorla RA (1988). Pavlovian conditioning: it's not what you think it is. Am Psychol 43: $151-160$.

Rolls ET, Critchley HD, Mason R, Wakeman EA (1996). Orbitofrontal cortex neurons: role in olfactory and visual association learning. J Neurophysiol 75: 1970-1981.

Sawamoto N, Honda M, Okada T, Hanakawa T, Kanda M, Fukuyama H et al (2000). Expectation of pain enhances responses to non-painful somatosensory stimulation in the anterior cingulate cortex and parietal operculum/posterior insula: an event-related functional magnetic resonance imaging study. J Neurosci 20: 7438-7445.

Schultz W (2006). Behavioral theories and the neurophysiology of reward. Ann Rev Psychol 57: 87-115.

Schweinhardt P, Seminowicz DA, Jaeger E, Duncan GH, Bushnell MC (2009). The anatomy of the mesolimbic reward system: a link between personality and the placebo analgesic response. J Neurosci 29: 4882-4887.

Scott DJ, Stohler CS, Egnatuk CM, Wang H, Koeppe RA, Zubieta JK (2007). Individual differences in reward responding explain placebo-induced expectations and effects. Neuron 55: 325-336. This paper suggests that placebo responsiveness depends on the efficiency of reward mechanisms, for a correlation between placebo responses and monetary rewards was observed.

Scott DJ, Stohler CS, Egnatuk CM, Wang H, Koeppe RA, Zubieta JK (2008). Placebo and nocebo effects are defined by opposite opioid and dopaminergic responses. Arch Gen Psychiatry 65: 1225-1226.

Setlow B, Schoenbaum G, Gallagher M (2003). Neural encoding in ventral striatum during olfactory discrimination learning. Neuron 38: 625-636.

Stewart-Williams S, Podd J (2004). The placebo effect: dissolving the expectancy versus conditioning debate. Psychol Bull 130: 324-340.

Stockhorst U, Gritzmann E, Klopp K, Schottenfeld-Naor Y, Hübinger A, Berresheim HW et al (1999). Classical conditioning of insulin effects in healthy humans. Psychosom Med 61: 424-435.

Stockhorst U, Steingruber HJ, Scherbaum WA (2000). Classically conditioned responses following repeated insulin and glucose administration in humans. Behav Brain Res 110: 143-159.
Strafella AP, Ko JH, Monchi O (2006). Therapeutic application of transcrania magnetic stimulation in Parkinson's disease: the contribution of expectation. Neuroimage 31: 1666-1672.

Sunshine A, Laska E, Meisner M, Morgan S (1964). Analgesic studies of indomethacin as analyzed by computer techniques. Clin Pharmacol Ther 5: 699-707.

Terman GW, Morgan MJ, Liebeskind JC (1986). Opioid and non-opioid stress analgesia from cold-water swim: importance of stress severity. Brain Res 372: 167-171

Thompson PM, Hayashi KM, de Zubicaray G, Janke AL, Rose SE, Semple J et al (2003). Dynamics of gray matter loss in Alzheimer's disease. J Neurosci 23: 994-1005.

Tobler PN, Fiorillo CD, Schultz W (2005). Adaptive coding of reward value by dopamine neurons. Science 307: 1642-1645.

Tolman EC (1932). Purposive Behavior in Animals and Men. Appleton Century Crofts: New York.

Vase L, Robinson ME, Verne GN, Price DD (2005). Increased placebo analgesia over time in irritable bowel syndrome (IBS) patients is associated with desire and expectation but not endogenous opioid mechanisms. Pain 115: 338-347.

Voudouris NJ, Pech CL, Coleman G (1989). Conditioned response models of placebo phenomena: further support. Pain 38: 109-116.

Voudouris NJ, Pech CL, Coleman G (1990). The role of conditioning and verbal expectancy in the placebo response. Pain 43: 121-128.

Wager TD, Billing JK, Smith EE, Sokolik A, Casey KL, Davidson RJ et al (2004). Placebo-induced changes in $\mathrm{FMR}$ in the anticipation and experience of pain. Science 303: 1162-1166.

Wager TD, Scott DJ, Zubieta JK (2007). Placebo effects on human $\mu$-opioid activity during pain. Proc Nat Acad Sci USA 104: 11056-11061.

Willer JC, Albe-Fessard D (1980). Electrophysiological evidence for a release of endogenous opiates in stress-induced 'analgesia' in man. Brain Res 198: 419-426.

Woods SC (1972). Conditioned hypoglycemia: effect of vagotomy and pharmacological blockade. Am J Physiol 223: 1424-1427.

Woods SC, Alexander KR, Porte Jr D (1972). Conditioned insulin secretion and hypoglycemia following repeated injections of tolbutamide in rats. Endocrinology 90: 227-231.

Woods SC, Makous W, Hutton RA (1968). A new technique for conditioned hypoglycemia. Psychon Sci 10: 389-390.

Woods SC, Makous W, Hutton RA (1969). Temporal parameters of conditioned hypoglycemia. J Comp Physiol Psychol 69: 301-307.

Zhang W, Gardell S, Zhang D, Xie JY, Agnes RS, Badghisi H et al (2009). Neuropathic pain is maintained by brainstem neurons co-expressing opioid and cholecystokinin receptors. Brain 132: 778-787.

Zubieta JK, Bueller JA, Jackson LR, Scott DJ, Xu Y, Koeppe RA et al (2005). Placebo effects mediated by endogenous opioid activity on $\mu$-opioid receptors. J Neurosci 25: 7754-7762. 